\title{
Comparison of the Fatty Acid Composition of Peanut Butter by Applying Different Fat Extraction Procedures
}

\begin{abstract}
MIOARA NEGOITA, ADRIANA LAURA MIHAI*, ALINA ADASCALULUI, ENUTA IORGA, NASTASIA BELC
National Research \& Development Institute for Food Bioresources, IBA Bucharest, 6 Dinu Vintila Str., 021102, Bucharest, Romania

The aim of this work was to evaluate the influence of different fat extraction procedures on the fatty acids composition (FAs) of a NIST standard reference material, peanut butter (SRM ${ }^{\circledR} 2387$ ). Extraction of fat was made with petroleum ether by applying six extraction procedures: Soxhletautomatic with Büchi B-811 unit: Soxhlet standard (SS); Soxhlet warm (SW); Hot extraction (HE) and Continuous flow (CF), repeated extraction with solvent (SR) and Soxhlet traditional extraction (ST), by using a Soxhletextractor. Identification of FAMEs was based on retention time $(R T)$ and the ratio of characteristic ions $(\mathrm{m} / \mathrm{z})$ of the reference standards F.A.M.E. Mix C4-C24 and SRM ${ }^{\circledR} 2377$. FAMEs determination was realized by using internal standards (IS) and applying relative response factors $\left(R R F_{i}\right)$, and without IS by applying correction factors $\left(F_{i}\right)$. Determination of FAMEs was performed on a GC-MS. Triglyceride of pentadecanoic acid (TAG-IS C15:0) was used as an IS to assess the analyte losses during FAMEs preparation steps, and tricosanoic acid methyl ester (FAME-IS C23:0) was used to evaluate the analyte losses on GC injection. Values of fat content and fatty acids composition determined by the 6 extraction procedures were compared with the NIST certified values of SRM ${ }^{\circledR} 2387$. All 4 procedures of extraction made with Büchi unit B-811 were effective in fat extraction and analysis of fatty acids composition compared to standard methods. Between the experimentally determined values and the certified values there were no significant differences.
\end{abstract}

Keywords: extraction, fat, fatty acids, GC-MS

Nowadays, there are known different extraction methods for fat and fatty acids determination, depending on the matrix characteristics. The most used methods for fat extraction are the Soxhlet method, and the ones described by Folch et al. (1957) and Bligh and Dyer (1959) [1]. Lately, the fat extraction it is carried out with an automated extraction apparatus by applying different extraction procedures depending on the food characteristics [2]. There are trying to be used rapid analytical methods for the fat extraction which can improve the lipid recovery efficiency, which are faster, and requires less consumption of solvents. In order to overcome the limitation of conventional Soxhlet extractor, to improve the extraction procedure different procedures were used like: focused microwave-assisted Soxhlet extractor $[3,4]$, ultrasound-assisted Soxhlet extractor [5,6], high-pressure Soxhlet extractor. Accelerated solvent extraction was also used for fat extraction from three beef tissues [7] but it was shown that at high temperature and pressure the PUFAs and conjugated linoleic acids are altered. Sylwester et al. (2016) [8] showed that infrared and Raman spectroscopy are methods that can be used as well for fat quantification in potato chips, replacing the extraction method.

For fatty acids determination the most used methods are gas chromatography (GC) coupled with mass spectrometry (MS) [9-12] or flame ionization detector (FID) [13-19] and NMR technique [10, 20]. Gas chromatography is a precise method in the study of the variation or determination of fatty acid profiles in vegetable oils/ vegetable or animal fats or to study the modification of the fatty acids composition in food products obtained through different technological processes. For a better identification and quantification of fatty acids, the compounds are converted into corresponding FAMEs with higher volatility through different derivatisation process. In order to transform TAGs and FAs into FAMEs, a methylation process of free fatty acids is needed and can be realized in base hydrolysis or acid hydrolysis.

The objective of this work was to evaluate the fat extraction efficiency and the method accuracy of fatty acids quantification from peanut butter (SRM ${ }^{\circledR 2387 \text { ) }}$ compared with the NIST certified values of this standard reference material.

Fat extraction of peanut butter was realized through the automatic Soxhlet procedure with 4 different extraction programs (Soxhlet standard - SS; Soxhlet warm - SW; Hot extraction - HE and Continuous flow - CF), the Soxhlet traditional - ST procedure with an extractor and the SR EN ISO 17189:2005 - SR [21] extraction method, and the fat content determined was compared with the NIST certified value of SRM ${ }^{\circledR} 2387$. The fatty acids profile of peanut butter fat extracted through these different procedures was evaluated with the certified value by comparing the absolute difference between the certified value and the measured value $\left(\Delta_{\mathrm{m}}\right)$ with the expanded uncertainty $\left(U_{\Delta}\right)$ of the certified reference material. Where there is no significant difference between the measurement resultand the certified NIST value, the results should be $\Delta_{m} \leq U_{\Delta}[22]$.

\section{Experimental part}

Standards and reagents

A standard mixture of 37 FAMEs (F.A.M.E. Mix. C4-C24, Cat.No. 18919-1AMP, Bellefonte, PA, USA), and a mixture of reference standards of 26 FAMEs (SRM ${ }^{\circledR} 2377$, the National Institute of Standards \& Technology, USA) were used for peaks identification by retention time, confirmation of characteristic ions monitored $(\mathrm{m} / \mathrm{z})$, and for quantification of fatty acids.

*email: mihai_laura21@yahoo.com 
Table 1

NIST CERTIFIED AND REFERENCE MASS FRACTION VALUES FOR FAT AND SELECTED FATTY ACIDS AS FREE FATTY ACIDS IN SRM ${ }^{\circledR 2387}$

\begin{tabular}{|c|c|c|c|}
\hline Fat and fatty acids & FAMEs Code & $\begin{array}{l}\text { Mass fraction (g/l00 } \\
\mathrm{g})\end{array}$ & $\begin{array}{l}\text { Coverage } \\
\text { factor, } k\end{array}$ \\
\hline \multicolumn{4}{|c|}{ NIST certified mass fraction values } \\
\hline Fat (extractable) & - & $51.6 \pm 1.4$ & 2.57 \\
\hline Fat (as the sum of fatty acids as tryglicerides) & - & $49.8 \pm 1.9$ & 2.20 \\
\hline Saturated fatty acids (SFA) & - & $10.4 \pm 0.2$ & 2.04 \\
\hline Tetradecanoic Acid/Myristic Acid & C14:0 $0^{1,2}$ & $0.024 \pm 0.002$ & 2.20 \\
\hline Hexadecanoic Acid/ Palmitic Acid & C16:0 $0^{1,2}$ & $4.94 \pm 0.15$ & 2.16 \\
\hline Octadecanoic Acid/ Stearic Acid & C18:0 $0^{1,2}$ & $2.13 \pm 0.008$ & 2.16 \\
\hline Eicosanoic Acid/ Arachidic Acid & $\mathrm{C} 20: 0^{1,2}$ & $0.710 \pm 0.029$ & 2.20 \\
\hline Docosanoic Acid/ Behenic Acid & $\mathrm{C} 22: 0^{1,2}$ & $1.81 \pm 0.08$ & 2.12 \\
\hline Tetracosanoic Acid/ Lignoceric Acid & $\mathrm{C} 24: 0^{1,2}$ & $0.781 \pm 0.044$ & 2.23 \\
\hline Monounsaturated fatty acids (MUFA) & - & $24.4 \pm 0.9$ & 2.20 \\
\hline cis-9-Hexadecenoic Acid/ Palmitoleic Acid & $\mathrm{C} 16: \ln 7^{1,2}$ & $0.044 \pm 0.010$ & 2.36 \\
\hline cis-9-Octadecenoic Acid/ Oleic Acid & C18: $\ln 9^{1,2}$ & $23.38 \pm 0.90$ & 2.20 \\
\hline cis-11-Octadecenoic Acid/ Vaccenic Acid & $\mathrm{C} 18: \ln 7^{1}$ & $0.255 \pm 0.016$ & 2.45 \\
\hline cis-11-Eicosenoic Acid/ Gondoic Acid & $\mathrm{C} 20: \ln 9^{1,2}$ & $0.643 \pm 0.031$ & 2.26 \\
\hline Polyunsaturated fatty acids (PUFA) & - & $13.2 \pm 0.4$ & 2.16 \\
\hline cis-9,12-Octadecadienoic Acid/Linoleic Acid & $\mathrm{C} 18: 2 \mathrm{n} 6^{1,2}$ & $13.15 \pm 0.41$ & 2.16 \\
\hline cis-9,12,15-Octadecatrienoic Acid/ $\alpha$-Linolenic Acid & $\mathrm{C} 18: 3 \mathrm{n} 3^{1,2}$ & $0.030 \pm 0.001$ & 2.18 \\
\hline \multicolumn{4}{|c|}{ Reference mass fraction values } \\
\hline Heptadecanoic Acid/ Margaric Acid & $\mathrm{C} 17: 0^{2}$ & $0.048 \pm 0.001$ & 2.05 \\
\hline cis-9-Heptadecenoic Acid & $\mathrm{C} 17: \ln 7^{2}$ & $0.033 \pm 0.006$ & 2.78 \\
\hline cis-13-Docosenoic Acid/ Erucic Acid & $\mathrm{C} 22: \ln 9^{1,2}$ & $0.054 \pm 0.012$ & 2.57 \\
\hline cis-11,14-Eicosadienoic Acid & $\mathrm{C} 20: 2 \mathrm{n} 6^{2}$ & $0.016 \pm 0.007$ & 3.18 \\
\hline cis-5,8,11,14-Eicosatetraenoic Acid/Arachidonic Acid & $\mathrm{C} 20: 4 \mathrm{n} 6^{1,2}$ & $0.024 \pm 0.015$ & 4.30 \\
\hline
\end{tabular}

${ }^{1}$ found in SRM $2377,{ }^{2}$ found in F.A.M.E. Mix C4-C24

For evaluation of analyte losses on GC injection was used as internal standard, tricosanoic acid methyl ester (FAME-IS C23:0), purchased from Sigma-Aldrich (St. Louis, MO, USA, purity >99\%). FAME-IS stock solution of $5 \mathrm{mg} /$ $\mathrm{mL}$ concentration was prepared in isooctane.

Also for recovery calculation, for evaluation of analyte losses during TAGs and FAs transformation into FAMEs was used the second internal standard, pentadecanoic acid triglyceride (TAG-ISC15:0), purchased from Sigma-Aldrich (St. Louis, MO, USA, purity >98\%). Solution of TAG-IS C15:0 of $4 \mathrm{mg} / \mathrm{mL}$ concentration was prepared in isooctane.

Petroleum ether, fraction $40-60^{\circ}$ (VWR Chemicals, France), was the solvent used for fat extraction.

Methanolic solution of sodium hydroxide $5.4 \mathrm{M}$ concentration (Acros, New Jersey), methanolic solution of boron trifluoride 14\% (Sigma Aldrich, Switzerland) and sodium chloride (Sigma Aldrich, Denmark) were used for FAMEs preparation. Methanol and isooctane were of analytical grade, specially for chromatography use (SigmaAldrich, Germany).

The experiments were performed using a standard reference material SRM ${ }^{\circledR 2387}$ (Peanut butter) NIST certified (Gaithersburg, MD 20 899), with certified values shown in table 1.

\section{Sample preparation for fat determination}

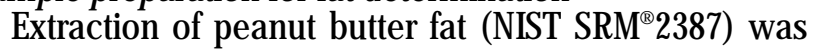
conducted with petroleum ether, fraction $40-60^{\circ}$, by applying of six extraction procedures.

Extraction of peanut butter fat by using the automated extraction system Buchi B-811 (SS, SW, HE, CF)

Fat extraction was achieved by applying the four possible extraction procedures of the Buchi Universal Extraction System B-811 (Switzerland) (SS, SW, HE and CF). All these extraction approaches follow three steps, an extraction step, a rinsing step and a drying step of the extract, under nitrogen flow.
The presence of the two heating elements (lower and upper) on each extraction position, it allows the control of extraction steps by the optical sensors in order to optimize the extraction time and, at the same time reducing the solvent consumption.

Briefly, sample were extracted by putting $20 \mathrm{~g}$ of quartz sand in the sample tube, adding one round-filter paper on top, then another $20 \mathrm{~g}$ of sand and $10 \mathrm{~g}$ of sodium sulfate anhydrous. Approximative $2 \mathrm{~g}$ of sample is added on top of the sodium sulfate anhydrous and comminuted with it. After this, $20 \mathrm{~g}$ of sand is added and mixed with the other layer. On top is added another $20 \mathrm{~g}$ of sand and the sample tube is put in the extraction system.

Another step involves the beakers preparation for solvent extraction. Empty beakers were dried in an oven set at $105^{\circ} \mathrm{C}$, cool down in a desiccator for $30 \mathrm{~min}$, and weighted prior to extraction. After the extraction programme is finished, the extracted lipids were collected in beakers which were dried in a vacuum oven ( $1 \mathrm{~h}$ at $40^{\circ} \mathrm{C}, 200 \mathrm{mbar}$ ), then let to room temperature for $30 \mathrm{~min}$ in a desiccator and weighted. The percent of crude fat was calculated. The procedure was performed in four replicates and the average mean and standard deviation were calculated.

By using the extraction unit B-811 it was realised the drying in an inert gas atmosphere (nitrogen), useful in the determination of FAMEs, in order to prevent fat oxidation.

The working conditions for the four extraction approaches are shown in table 2.

Extraction of fat from peanut butter by applying SR EN ISO 17189:2005 method (SR)

Fat extraction by applying the standard SR EN ISO 17189:2005 [21] is a reference method for determining the fat content of butter, edible oil, emulsions and spreadable fats. Compared to the application of the extraction system Büchi B-811 and Soxhlet extractor where the sample preparation requires temperatures higher than $100^{\circ} \mathrm{C}$, the application of this method requires temperatures 


\begin{tabular}{|c|c|c|c|c|c|}
\hline \multirow[t]{2}{*}{ No. } & \multirow{2}{*}{$\begin{array}{l}\text { Extraction } \\
\text { method }\end{array}$} & \multirow{2}{*}{$\begin{array}{l}\text { Solvent } \\
\text { volume, } \\
\mathrm{mL}\end{array}$} & \multicolumn{3}{|l|}{ Program characteristics } \\
\hline & & & steps & heating elements level & time (min) \\
\hline \multirow[t]{4}{*}{1.} & \multirow{4}{*}{$\begin{array}{l}\text { Soxhlet } \\
\text { Standard } \\
\text { (SS) }\end{array}$} & \multirow[t]{4}{*}{90} & extraction & $8^{*}$ & 90 \\
\hline & & & rinsing & $8^{*}$ & 20 \\
\hline & & & \multirow{2}{*}{$\begin{array}{l}\text { drying under nitrogen } \\
\text { atmosphere }\left(\mathrm{P}_{\mathrm{N} 2}=2 \text { bar }\right)\end{array}$} & $4^{*}$ & 10 \\
\hline & & & & $3^{*}$ & 30 \\
\hline \multirow[t]{5}{*}{2.} & \multirow{5}{*}{$\begin{array}{l}\text { Hot } \\
\text { extraction } \\
\text { (HE) }\end{array}$} & \multirow[t]{5}{*}{140} & \multirow{2}{*}{$\begin{array}{l}\text { atmosphere }\left(\mathrm{P}_{\mathrm{N} 2}=2 \mathrm{bar}\right) \\
\text { extraction }\end{array}$} & $8^{*}$ & \multirow[t]{2}{*}{90} \\
\hline & & & & $2^{* *}$ & \\
\hline & & & rinsing & $8^{*}$ & 20 \\
\hline & & & \multirow{2}{*}{$\begin{array}{l}\text { drying under nitrogen } \\
\text { atmosphere }\left(\mathrm{PN}_{2}=2 \text { bar }\right)\end{array}$} & $4^{*}$ & 10 \\
\hline & & & & $3^{*}$ & 30 \\
\hline \multirow[t]{5}{*}{3.} & \multirow{5}{*}{$\begin{array}{l}\text { Warm } \\
\text { extraction } \\
\text { (SW) }\end{array}$} & \multirow[t]{5}{*}{80} & \multirow[t]{2}{*}{ extraction } & $8^{*}$ & \multirow[t]{2}{*}{90} \\
\hline & & & & $2^{* *}$ & \\
\hline & & & rinsing & $8^{*}$ & 20 \\
\hline & & & \multirow{2}{*}{$\begin{array}{l}\text { drying under nitrogen } \\
\text { atmosphere }\left(\mathrm{P}_{\mathrm{N} 2}=2 \text { bar }\right)\end{array}$} & $4^{*}$ & 10 \\
\hline & & & & $3^{*}$ & 30 \\
\hline \multirow[t]{4}{*}{4.} & \multirow{4}{*}{$\begin{array}{l}\text { Continuous } \\
\text { flow }(\mathrm{CF})\end{array}$} & \multirow[t]{4}{*}{80} & extraction & $8^{*}$ & 90 \\
\hline & & & rinsing & $8^{*}$ & 20 \\
\hline & & & \multirow{2}{*}{$\begin{array}{l}\text { drying under nitrogen } \\
\text { atmosphere }\left(\mathrm{P}_{\mathrm{N} 2}=2 \text { bar }\right)\end{array}$} & $4^{*}$ & 10 \\
\hline & & & & $3^{*}$ & 30 \\
\hline
\end{tabular}

Table 2

WORKING PARAMETERS FOR THE FOUR FAT EXTRACTION METHODS OF PEANUT BUTTER

WITH AUTOMATED

EXTRACTION SYSTEM

BUCHI B-811

*heating level of lower heating element **heating level of upper heating element

of up to $40^{\circ} \mathrm{C}$, temperature being an important factor in fat oxidation.

The fat from peanut butter was extracted based on repeated solvent extraction using petroleum ether. About $2 \mathrm{~g}$ of the peanut butter was weighted into a centrifuge tube and $20 \mathrm{~mL}$ solvent was added. The sample was mixed well with the solvent, on a rotatory shaker Vortex (Heidolph Multi Reax, Heidolph Instruments GmbH \& Co.KG), then the resulting mixture is allowed to separate by centrifugation using an Eppendorf centrifuge (EPPENDORF AG, Germany), at a temperature of $24^{\circ} \mathrm{C}$ for $5 \mathrm{~min}$ at 6500 rpm and the supernatant fluid was decanted into a weighted flask for rotary evaporator. Two others extractions were performed under the same conditions with $20 \mathrm{~mL}$ solvent. The supernatant was added to the previous extract. The solvent was evaporated using a rotary evaporator under vacuum (rotary evaporator R-210, BUCHI Labortechnik AG, Germany), then traces of solvent were removed by placing the flask in a vacuum oven (VO200-Thermobblech, Memmert $\mathrm{GmbH}+\mathrm{Co} . \mathrm{KG}$ ) and kept at $40^{\circ} \mathrm{C}, 200 \mathrm{mbar}$ pressure for $1 \mathrm{~h}$. The fat content was determined gravimetrically by weighting the mass of substances extracted and was expressed in \% fat. The procedure was performed in nine replicates and the average mean and standard deviation were calculated.

\section{Extraction of fat from peanut butter using a traditional} Soxhlet extractor (ST)

About $3 \mathrm{~g}$ of sample was introduced into an extraction thimble on which were added approximatively $3 \mathrm{~g}$ of sodium sulfate anhydrous and $210 \mathrm{~mL}$ of petroleum ether. The solvent was heated to boiling, then it condensed in refrigerant and returns back into the cartridge containing the sample to be extracted. By performing several cycles of extraction (duration 5-6 h), the fat extraction was accomplished. Fatobtained was brought to constant weight in an oven set at $105^{\circ} \mathrm{C}$, for $1 \mathrm{~h}$ and fat content was determined by gravimetry. For this extraction method three replicates were performed and the average mean and standard deviation were calculated.

Preparation of FAMEs from fatextracted from peanut butter To determine the total, saturated, monounsaturated and polyunsaturated fatty acids, lipids extracted from peanut butter (SRM ${ }^{\circledR 2387}$ ) using each extraction procedure were converted to corresponding FAMEs by transesterification with methanolic solution of sodium hydroxide and boron trifluoride (SR EN ISO 12966-2:2011) [23].

Approximately $50 \mathrm{mg}$ of the fat extracted was transferred to a volumetric flask of $50 \mathrm{~mL}$ and $250 \mu \mathrm{L}$ TAGIS C15:0 solution $4 \mathrm{mg} / \mathrm{mL}$ concentration was added. Fat was dissolved in $4 \mathrm{~mL}$ of $0.5 \mathrm{M}$ solution of $\mathrm{CH}_{3} \mathrm{ONa}$ and then was placed in a water bath and kept at $60^{3}-70^{\circ} \mathrm{C}$ for about 1-2 min. After this step, $5 \mathrm{~mL}$ of a methanolic solution of $\mathrm{BF}_{3} 14 \%$ concentration is added, sample was kept in the water bath at reflux for a further $3 \mathrm{~min}$. To extract the FAMEs, $3 \mathrm{~mL}$ isooctane were added into the flask and sample was kept for $1 \mathrm{~min}$ in the water bath. After removing the flask from the reflux, $15 \mathrm{~mL}$ of saturated $\mathrm{NaCl}$ solution was added immediately, and solution is stirred vigorously for approximately $15 \mathrm{~s}$. Then it was added another $20 \mathrm{~mL}$ of saturated $\mathrm{NaCl}$ solution, and stirred lightly. Sample is shaken vigorously and after layer separation, the upper isooctane layer which contains the FAMEs is transferred through a filter of sodium sulphate anhydrous in a $4 \mathrm{~mL}$ vial. The extract obtained was diluted with isooctane. Extract diluted solution was fortified with FAME-IS C23:0, so the final extract concentration in FAME-IS is $50 \mu \mathrm{g} / \mathrm{mL}$. The final extract with FAME-IS was transferred to an autosampler vial for $\mathrm{GC}$ analysis.

\section{FAMEs analysis and operating condition of GC-MS}

FAMEs analysis was performed in accordance with SR EN ISO 12966-4:2015 [24], with changes from the reference, by using of a gas chromatograph coupled with a mass spectrometer (Trace GC Ultra/TSQ Quantum XLS, Thermo Fisher Scientific, USA). A high polarity capillary column, TR-FAME ( $60 \mathrm{~m} \times 0.25 \mathrm{~mm} \times 0.25 \mu \mathrm{m})$ was used. Analysis of the derivatized extractsamples were performed in the positive electron impact ionization $\left(\mathrm{El}^{+}\right)$mode, SIM mode (Selected Ion Monitoring) using 24 segments. The ion source temperature was $250^{\circ} \mathrm{C}$, the oven temperature was programmed at $100^{\circ} \mathrm{C}$ for $0.2 \mathrm{~min}$, increased to $240^{\circ} \mathrm{C}$ with $2^{\circ} \mathrm{C} / \mathrm{min}$ and hold for $15 \mathrm{~min}$. At this temperature it was used as a mobile phase He of purity $99.9995 \%$ (5.0), at a constant flow rate of $1 \mathrm{~mL} / \mathrm{min}$. A volume of $0.5 \mu \mathrm{L}$ of extract was injected at $240^{\circ} \mathrm{C}$ in split mode with a 1:50 split ratio and a $50 \mathrm{~mL} / \mathrm{min}$ splitting rate. Injections were performed in duplicate. Instrument control, data 
acquisition and processing were performed using the Xcalibur Program.

Identification of FAMEs from peanut butter (SRM ${ }^{\circledR 2387}$ ) samples was performed by comparison with retention times of FAME components from the reference standards used. The analysis of FAs composition in peanutbutter was made based on $\operatorname{RRF}_{i}(\mathrm{~g} / 100 \mathrm{~g})$, the results being corrected by applying of the obtained recovery by using internal standards (TAG-IS C15:0 and FAME-IS C23:0) and based on $\mathrm{F}_{\mathrm{i}}$ (weight \%).

\section{Identification and quantification of fatty acids}

FAMEs in peanut butter were identified by comparing the peak retention times (RT) with the peak RT of F.A.M.E. Mix C4-C24 and SRM ${ }^{\circledR} 2377$, and confirmation was realised based on characteristic ions monitored $(\mathrm{m} / \mathrm{z})$. Calibration curves were produced from six working standard solutions (S1a-S6a). Calibration solutions were prepared in isooctane, five injections were done for each standard, and were injected to GC-MS.

For the 26 FAMEs of the reference standard SRM ${ }^{\circledR 2} 2377$, the calibration curves were performed by plotting the graphical representation of the area ratio $A_{\text {EAME }} / A_{\text {IS }}$ based on FAME concentration $\left(C_{\text {FAME }}\right)$, Response ratio $=f\left(C_{\text {FAME }}\right)$ LINEAR or by graphical representation of the area ratio $A_{\text {FAME }}$ I $A_{\text {IS }}$ based on concentration ratio $\left(C_{\text {EAMF }} / C_{15}\right)$, "Response ratio $={ }^{\prime}\left(C_{F_{F A M}} / C_{1 S}\right)$ - AVERAGE RESPONSE" using IS, FAME-IS C23:0.

Limit of detection (LOD) and limit of quantification (LOQ) were determined according to International Cooperation on Harmonisation (ICH) guideline [25] and were calculated based on linear regression equation, area ratio $\left(A_{\text {EAME }} / A_{\text {IS }}\right)$ in relation with FAME concentration $\left(C_{\text {FAME }}\right)$, LOD/LOQ were expressed as detector response:

$$
L O D=\frac{3.3 \times S D}{b}, L O Q=\frac{10 \times S L}{b}
$$

where:

$S D$-standard deviation of calibration curves calculated with Steyx = Sy function

$b$-calibration curve slope

Based on the calibration curves Response ratio $=\mathrm{f}\left(\mathrm{C}_{\mathrm{FAME}}\right)$ $C_{1 s}$ ) - AVERAGE RESPONSE, made with SRM ${ }^{\circledR} 2377$, for each identified FAME there were calculated the relative response factors ( $\left.R R F_{i}\right)$.

Based on the composition of the reference standards SRM $^{\oplus 2377, ~ F . A . M . E . ~ M i x ~ C 4-C 24 ~ a n d, ~ d e p e n d i n g ~ o n ~ t h e ~}$ detector signal, the correction factors $\left(F_{i}\right)$ were calculated using the six concentration levels (S1-S6 for SRM ${ }^{\circledR 2} 237$; N1-N6 for F.A.M.E. Mix C4-C24) in order to quantify the fatty acids.

\section{Quantification of FAs based on RRF}

To obtain the RRF were prepared 6 working solutions on which was added the internal standard (FAME-ISC23:0). For each FAME, from SRM ${ }^{\circledR 2377}$ there were calculated the RRF $_{\text {. }}$ (mean of 5 injections of the calibration standard solutions) in relation with FAME-IS C23:0 which was added to the standard solutions to obtain a $50.0 \mu \mathrm{g} / \mathrm{mL}$ IS concentration.

These $\mathrm{RRF}_{\mathrm{i}}$ values were calculated using the following formula:

$$
R R F_{i}=\frac{\text { Area ratio }}{\text { Amount ratio }}
$$

where:

Area ratio - the ratio between FAME area and IS area

Amount ratio - the ratio between $\mathrm{FAME}_{\mathrm{i}}$ concentration and IS concentration
Based on RRF there were quantified the $F A_{i}(g / 100 g)$ from the peanut butter as follows:

$$
g F A i / 100 g=\frac{V \times \text { Area ratio } \times C_{F A M E}-I S \times L \times F_{F A i}}{w \times R R F i \times F_{t r}}
$$

where:

$V$ - the volume of FAME final extract in the sample (3 $\mathrm{mL})$

Area ratio - the ratio between FAMEi area and FAME-IS area from the final extract chromatogram

$C_{\text {FAME }}{ }^{-}$the maSS of FAME-IS added to the diluted final extract, in $\mu \mathrm{g}(50 \mu \mathrm{g})$

$L$ - lipid content of peanut butter, in \%

$F_{F A i}$ stoechiometic conversion factor of FAMEi into FAi

$W$ - the mass of sample taken into analysis, extracted from the peanut butter, $g$

$R R F i$ - relative response factor of FAME determined based on FAME-IS from the reference standard

$F_{\text {tr. }}$ the transformation factor from $\mu \mathrm{g}$ in $\mathrm{g}\left(\mathrm{F}_{\mathrm{t}}=10^{6}\right)$

The recovery was calculated based on the TAG-IS C15:0 and should be between $75 \%-120 \%$. In the case when the recovery is not between these limits, the procedure should be repeated. For the samples quantification based on $\mathrm{RRF}_{i^{\prime}}$ recovery was applied to the final result.

\section{Quantification of FAs based on $F$}

There were determined the $F_{\text {. }}$ of FAME from the composition of reference standards SRM ${ }^{\circledR} 2377$ and F.A.M.E. Mix C4-C24, by application of the instrumental method GCMS, according to SR EN ISO 12966-4: 2015 [24].

The calibration levels (S1-S6; N1-N6) of the reference standards were injected in the GC-MS. F were calculated for 40 FAME (of which 23 FAME are common to the reference standards SRM ${ }^{\circledR} 2377$ and F.A.M.E. Mix C4-C24, 3 are specific to SRM ${ }^{\circledR} 2377$, and 14 are specific to F.A.M.E. Mix C4-C24) for each level of calibration, and also was calculated the $F$ average for the 6 concentration levels (S1-S6; N1-N6) after 5 consecutive injections for each level.

Correction factors were calculated using the formula from the equation 4 :

$$
R R F_{i}=\frac{\text { Area ratio }}{\text { Amount ratio }}
$$

where:

$p$ - FAME mass percent from the mix of reference standards based on the certificate of analysis, \%

$\Sigma A i$ - sum of FAME area for all FAME from the chromatogram of reference standards

$A i$ - area of FAME from the chromatogram of reference standards.

Correction factors are used to correct the area percentage, according to the mass of each FAME from the reference standard.

Quantification of FA (weight \%) from peanutbutter was performed using the following formula (5):

$$
p \% F A_{i}=\frac{F_{i} \times A_{i}}{\sum\left(F_{i} \times A_{i}\right)} \times 100
$$

where:

$p$ - mass percent of individually FAMEi/FAi calculated as triacylglycerol/100 g fat, in \%

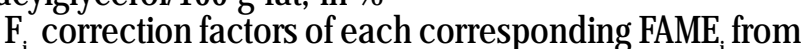
the reference standards

$\mathrm{Ai}$ - peak area of $\mathrm{FAME}_{\mathrm{i}}$ from the extracted fat chromatogram

$\Sigma\left(F_{x} \times A_{i}\right)$ sum of the result of $F_{i} \times A_{i}$ for all FAME peaks from the extracted fat.

According to the quality certificate of the NIST-certified reference material, SRM ${ }^{\circledR} 2387$ (table 1), from the $17 \mathrm{FA}$ 
specified (NIST-certified values and reference values), 13 $\mathrm{FA}$ are common to both reference standards, $1 \mathrm{FA}$ is specific to SRM ${ }^{\circledR 2} 2377$ and 3 are specific to the reference standard F.A.M.E. Mix C4-C24. For fatty acids determination from $S R M{ }^{\circledR} 2387$, based on $F_{i}$, all $17 \mathrm{FA}_{i}$ were identified and quantified.

\section{Measurement results evaluation}

Comparison of results obtained based on RRF, with certified values of $S R M^{\otimes} 2387$

Both, fat content and individual and total fatty acids composition (based on RRF.) of fats extracted from peanut butter through six extraction procedures, were compared to the NIST's certified values.

In order to verify that the determined fat content and the SFA, MUFA, and PUFA compositions of peanut butter, through the 6 extraction approaches, fall within the certified reference material values, the measurement results were compared with certified value [22]. This consists in comparing the absolute difference between the certified value and the measured value $\left(\Delta_{m}\right)$, with the expanded uncertainty $\left(U_{\Delta}\right)$.

$$
\Delta_{m}=\left|C_{m}-C_{S R M}\right|
$$

where:

$\Delta_{m}$ - the absolute difference between the measured average value and the certified value

$\mathrm{C}_{\mathrm{m}}$ - the measured average value

$C_{S R M}^{m}$ the certified value of the SRM ${ }^{\circledR} 2387$

The expanded uncertainty $\left(U_{1}\right)$ of the difference between the result and the certified value is obtained by multiplying the combined uncertainty $\left(u_{\ddot{A}}\right)$ with $k$.

$$
\begin{gathered}
\mathrm{U}_{\Delta}=k^{*} \mathrm{u}_{\Delta} \\
\mathrm{u}_{\Delta}=\sqrt{u_{m}^{2}+u_{S R M}{ }^{2}}
\end{gathered}
$$

where:

$U_{\Delta}$ - expanded uncertainty

$k^{\Delta}$ - coverage factor, corresponding to a confidence interval of about $95 \%$

$u$ the combined uncertainty of the result and the certified value

$u_{m}$-the uncertainty of the measurement result

$u_{S P M}$-the uncertainty of the certified value SRM ${ }^{\circledR 2387}$

Where there is no significant difference between the measurement result and the certified value, should be accomplished the condition $\Delta_{\mathrm{m}} \leq \mathrm{U}_{\Delta}$.

\section{Comparison of results obtained based on $F_{i}$ with certified} and references values of SRM ${ }^{\circledR} 2387$

The composition in fatty acids, individually and totally, of the fat extracted from peanut butter by the 6 extraction procedures, determined on the basis of the $F$. was evaluated according to SR EN ISO 12966-4:2015 [24]. Thus, it was required that the absolute difference bletween two independent a lalysis results $(\Delta)$, obtained by the same method, on identical test materials, in the same laboratory by the same operator using the same equipment, within a short timeframe, should not exceed the limit of repeatability $(r)$ in no more than $5 \%$ of cases.

\section{Results and discussions}

In order to obtain the most complete FA profile of SRM ${ }^{\circledR 2387}$, six different procedures to extract the fat were tested. For all these methods, petroleum ether was used as extraction solvent and FAMEs preparation was realized based on the same analytical procedure for the fat extracted through the six procedures. The extraction process and mass transfer of the unitBüchi are much faster, requiring less solvent consumption ( $90-140 \mathrm{~mL}$ per sample) and a shorter extraction time (2-3 h) compared with traditional Soxhlet extraction method, requiring a larger volume of organic solvents (> $200 \mathrm{~mL}$ per sample) and longer extraction times ( $>5 \mathrm{~h}$ per sample).

For the quantification of $F A$ from peanut butter as absolute content $(\mathrm{g} / 100 \mathrm{~g})$ there were used the RRF experimentally determined for each FAME using the $\mathrm{SRM}^{\circledR} 2377$ reference standard in relation with internal standard FAME-IS C23:0 used.

For the FA quantification as relative content expressed in weight \% there were used the determined $F$ from both reference standards used for identification (23 FAMEs common to both standards, 3 FAMEs specific to SRM ${ }^{\circledR} 2377$ and 14 FAMEs specific to F.A.M.E. Mix C4-C24).

\section{Extracted Fat Content}

The four fat extraction procedures (SS, HE, SW, CF) applied to the Buchi unit B-811 did not show significant differences $(p>0.05)$ in the fat content compared to standardized methods (SR, ST). There were no significant differences between the measured values $\left(C_{m}\right)$ and the certified value $\left(C_{S P M}\right)$ ( fig. 1), for each extraction procedure being fulfilled the condition $\Delta \leq \mathrm{U}$.

From the point of view of the fat content determined by the 6 extraction procedures compared to the certified value, there were no significant differences. For the standardized methods (SR and ST), the differences between the value of fat obtained and the certified value were the lowest, below $0.4 \%$, and for the 4 automatic extraction procedures (SS, HE, SW, CF) the differences were between $0.56 \% \div 1.74 \%$. Since the sistematic errors (bias) were not more than $\pm 2 \%$, it can be said that the six extraction methods are considered effective in extracting the peanut butter fat.

\section{Fatty acids composition based on RRF}

The fatty acids composition of peanut butter obtained after fat extraction through the 6 extraction procedures used was determined based on RRFi, established through the reference standard SRM ${ }^{\circledR 2} 2377$ in relation to FAME-IS $\mathrm{C} 23: 0$ (table $3 \mathrm{a}$ and table $3 \mathrm{~b}$ ). The absolute concentrations ( $\mathrm{g} \mathrm{FA} / \mathrm{l} 100 \mathrm{~g}$ ) were calculated using the recovery obtained

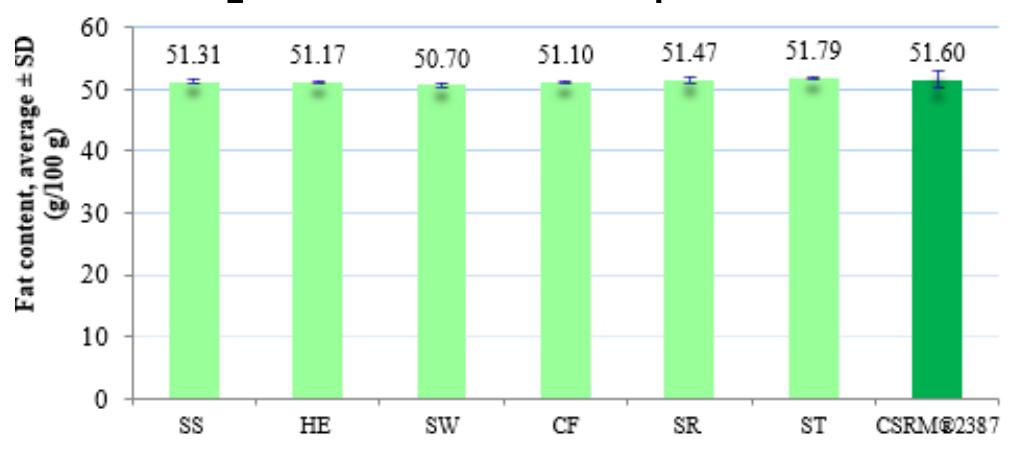

Fig. 1. Fat content (average $\pm S D$ ) experimentally determined $\left(C_{m}\right)$ in relation to the certified value $\left(\mathrm{C}_{\mathrm{SRM}}\right)$ of fat peanut butter $\left(\mathrm{SRM}^{\circledR} 2387\right)$

Fat extraction procedure 
using TAG-IS C15:0. For each extraction mode, the analysis was performed in six replicates.
Based on reference standard SRM ${ }^{\circledR} 2377$, twelve peaks of fatty acid methyl esters were identified according to SRM certified values (table 1).

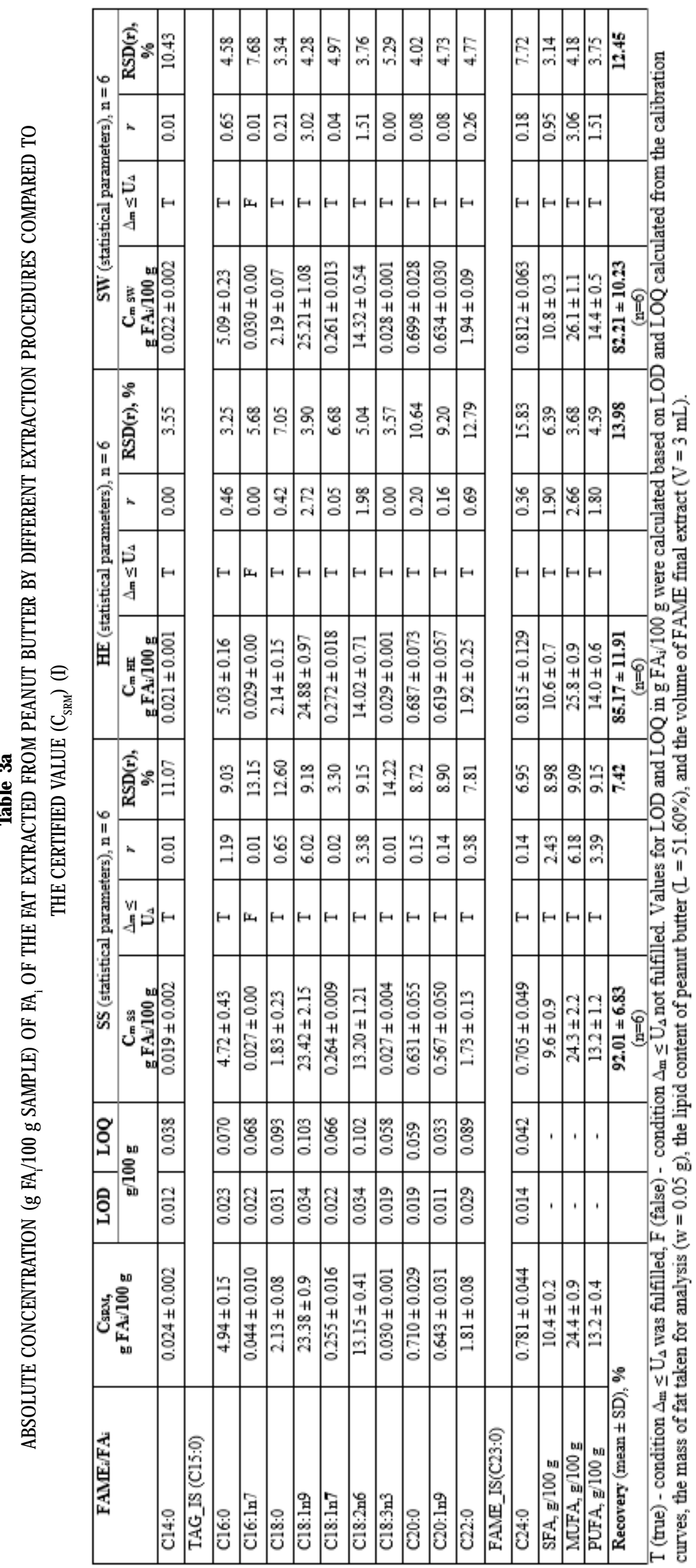


Among the measured values of the individual and total SFA content (table $3 a$ and table $3 b$ ), there were no significant differences compared to the certified value, the condition $\Delta_{m} \leq \mathrm{U}_{\text {. }}$ being fulfilled for the 6 saturated fatty acids from the peanut butter composition: myristic (C14:0), palmitic (C16:0), stearic (C18:0), arachidic (C20:0), behenic (C22:0) and lignoceric (C24:0) acids.

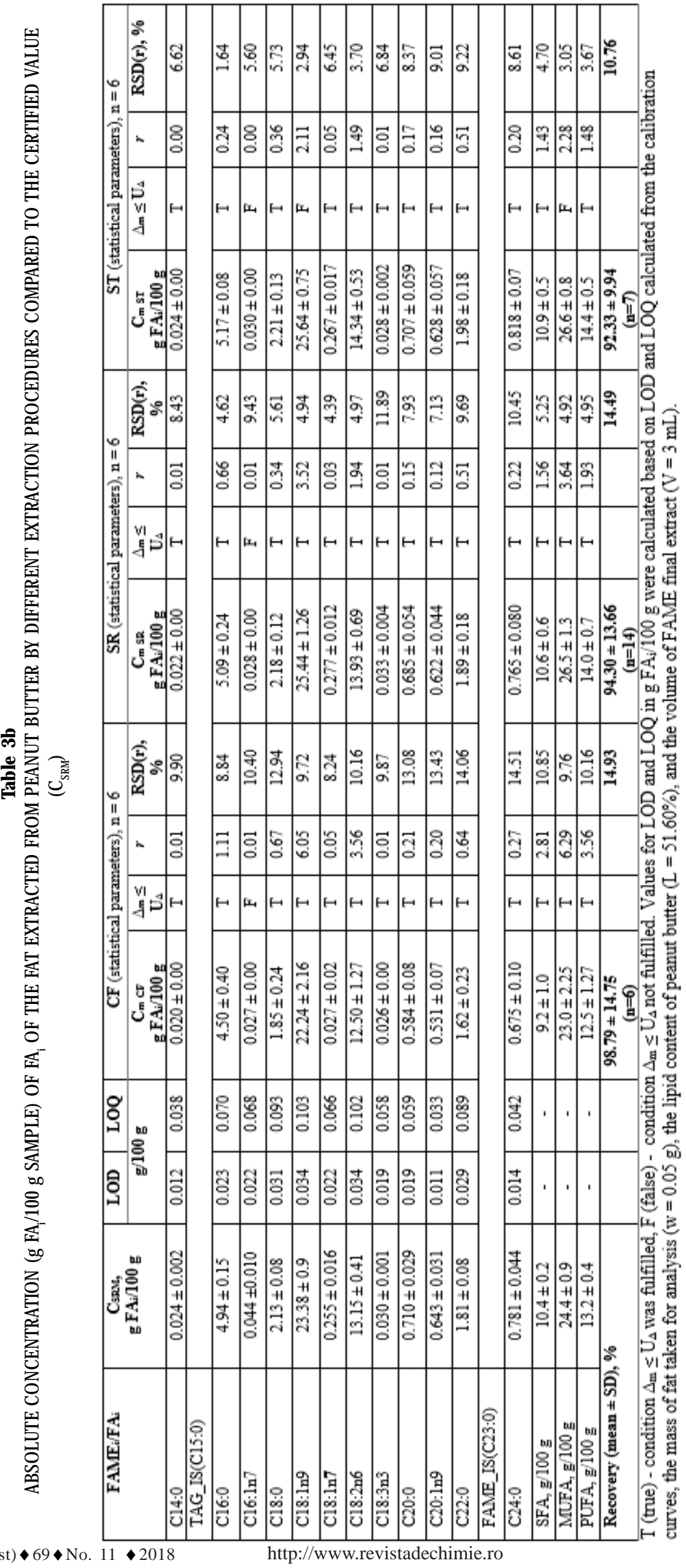


When determining the total MUFA content from fat extracted through ST method (table 3b), the measurement results showed significant differences from the certified value due to the lower content of palmitoleic acid, C16:1n7, and higher content of oleic acid, C18:1n9, extracted from the samples. The lower value determined for palmitoleic acid, C16:1n7, can be explained on the one hand by the fact that during the extraction process this compound degrades or on the other hand the values in which this compound is found are detectable butcan notbe quantified, the measured values for this compound being between the detection limit (LOD, $0.022 \mathrm{~g} / 100 \mathrm{~g})$ and the quantification limit (LOQ, $0.068 \mathrm{~g} / 100 \mathrm{~g}$ ).

In the case of oleic acid, it can be seen that this fatty acid was found in peanut butter in the highest percent. Salimon et al. (2013) [13] as well found that in the margarine samples analysed this fatty acid it was found like the predominant FA. When using the ST method, the determined value was higher than the certified value, with a percentage difference of $+9.67 \%$. The condition $\Delta_{m} \leq U$, notbeing performed individually and totally, for these acids, leads to the non-fulfillment of the monounsaturated fatty acid condition.

Between the measured values of the individual and total PUFA content (table $3 \mathrm{a}$ and table $3 \mathrm{~b}$ ), there were no significant differences from the certified value, the condition $\Delta \mathrm{m} \leq \mathrm{U}$ being accomplished for the two PUFA from the peanut butter composition (C18:2n 6 and $\mathrm{C} 18: 3 \mathrm{n} 3)$. The measured values for the total PUFA content were: $C_{\text {PRM }}(13.2 \pm 0.4 \mathrm{~g} / 100 \mathrm{~g}), C_{\text {mSS }}(13.2 \pm 1.2 \mathrm{~g} / 100 \mathrm{~g})$, $C_{\text {HE }}(14.0 \pm 0.6 \mathrm{~g} / 100 \mathrm{~g}), C_{m \text { sw }}(14.4 \pm 0.5 \mathrm{~g} / 100 \mathrm{~g}), C_{m \text { CF }}$ $(12.5 \pm 1.27 \mathrm{~g} / 100 \mathrm{~g}), C_{\mathrm{m} \mathrm{ST}}(14.4 \pm 0.5 \mathrm{~g} / 100 \mathrm{~g})$, and $\mathrm{C}_{\mathrm{m} \mathrm{SR}}$ $(14.0 \pm 0.7 \mathrm{~g} / 100 \mathrm{~g})$.

The results obtained with respect to the fatty acid composition of peanut butter were calculated by applying the recovery (table $3 \mathrm{a}$ and table $3 \mathrm{~b}$ ). Recovery evaluation was performed by adding in the fat sample of the internal standard, triglyceride of pentadecanoic acid (TAG-ISC15:0) and adding to the final extract of tricosanoic acid methyl ester (FAME-IS C23:0) before injection to GC.

The data obtained show that the FAMEs preparation method is effective for triglyceride esterification, yielding an average recovery of $90.74 \%$ (recovery between $82.21 \%$ $\div 98.79 \%$ ). According to results, the best recovery percentage was obtained for Soxhlet under continuous flow $(98.79 \%)$. Even though the difference between the recovery values were significant, the values were considered valid in regard to the complexity of peanut butter [15].

The RSD $(r)$ values, under repeatability conditions $(n=$ 6), for the 6 extraction procedures for the 12 fatty acids from the NIST certified reference material composition, ranged between $1.64 \div 15.83 \%$. Higher values were generally obtained for compounds (C14:0; C16:1n7; C18:3n3) found in a lower quantity in the NIST certified reference material, having the determined values between LOD $(0.012 \div 0.022 \mathrm{~g} / 100 \mathrm{~g})$ and LOQ $(0.038 \div 0.068 \mathrm{~g} /$ $100 \mathrm{~g})$.

\section{Fatty acid composition based on $F$}

Correction factors established based on reference standards (SRM ${ }^{\circledR 2377, ~ F . A . M . E . ~ M i x ~ C 4-C 24) ~ w e r e ~ u s e d ~ t o ~}$ determine the relative concentration of FA. (weight $\%$ of total identified FAs) of the fat extracted through the 6 extraction procedures (tables $4 a$ and table $4 b$ ). Based on these reference standards, 17 peaks of FAMEs were identified, of which 12 FAMEs common to NIST certified values and 5 FAMEs common to reference values, according to the quality certificate (table 1).

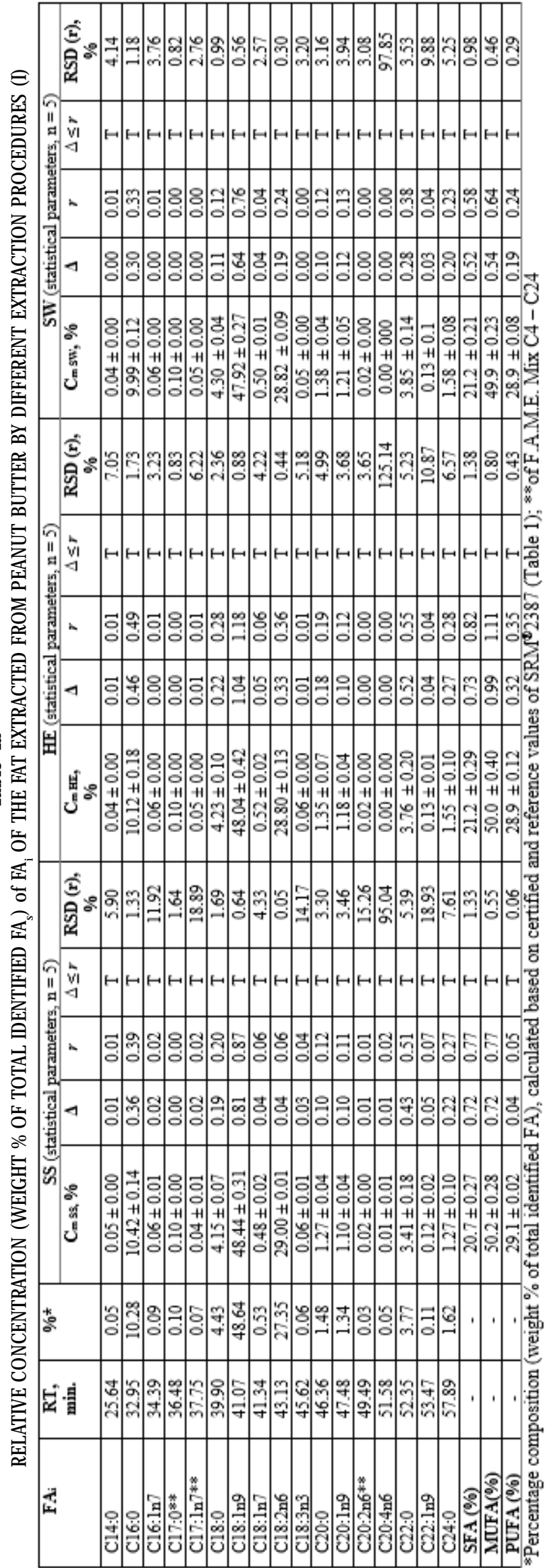

For the 6 extraction procedures of peanut butter tat, the absolute difference between 2 independent tests $(\Delta)$ is less than or equal to the repeatability limit $(r)(\Delta \leq r)$, both as the sum of SFA as well as individual ones for the 7 SFA from the peanut butter composition: myristic acid (C14:0), palmitic acid (C16:0), heptadecanoic acid (C17:0), stearic 
acid (C18:0), arachidic acid (C20:0), behenic acid (C22:0) and lignoceric acid (C24:0) (table $4 a$ and table 4b).

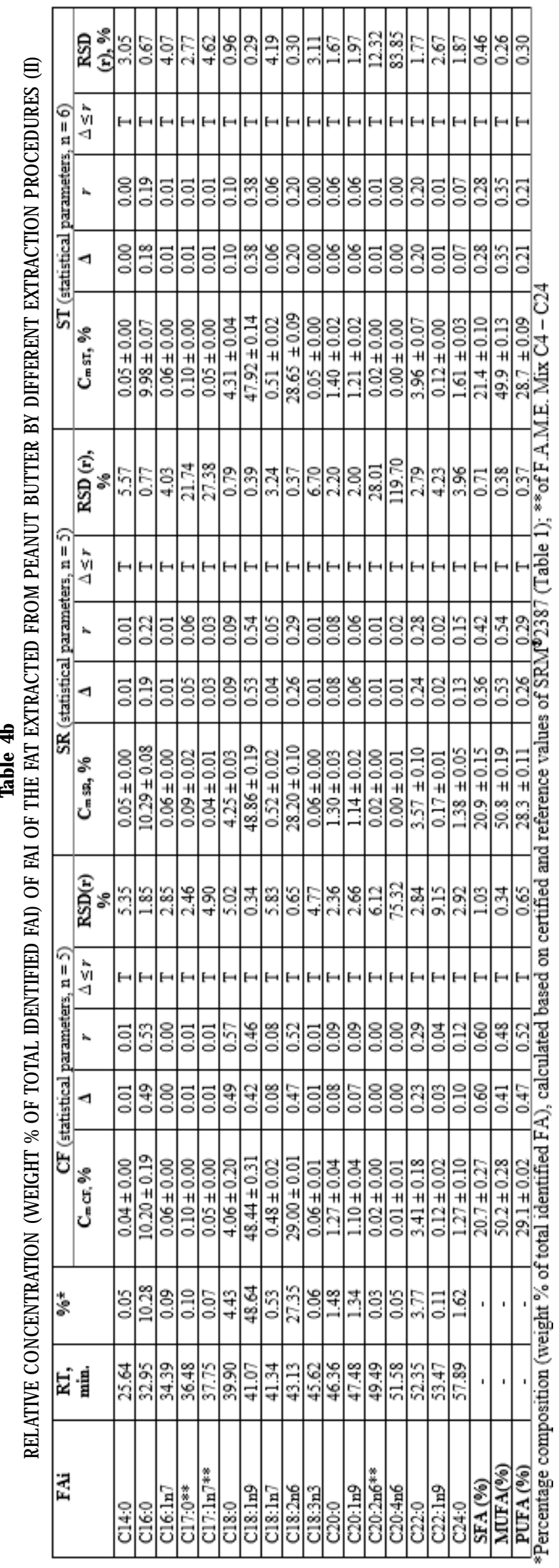

The required condition for the determined values of the fatty acid composition based on $\mathrm{F}$. was performed both for MUFA and for PUFA as the sum of acids and as individual acids.

From the data presented, it resulted that low RSD(r) values $(0.05 \div 5 \%)$ were obtained for compounds found in higher percentages $(1.00 \div 47 \%)$ and higher RSD(r) values $(6.00 \div 28 \%)$ for those found in lower percentages.

For arachidonic acid (C20:4n6), where the reference mass fraction was $0.024 \pm 0.015 \mathrm{~g} / 100 \mathrm{~g}(k=4.30)$, the obtained values of RSD(r) for the 6 different extraction procedures were between $75 \div 125 \%$. Taking into account the certified and reference values of the mass fraction from table 1, an indicative calculation of the percentage composition of the fatty acid content of the reference material can be made (table 4a) and it is observed that arachidonic acid (C20:4n6) is one of the components found in a very small amount $(0.05 \%)$.

The very high $\operatorname{RSD}(r)$ for arachidonic acid which is present in peanut butter may be because the determined values are below the LOD values $(0.007 \mathrm{~g} / 100 \mathrm{~g})$.

\section{Conclusions}

In this study, the fatty acid profiles of peanut butter (SRM ${ }^{\circledR} 2387$ ) were obtained using 6 different extraction procedures and using the same direct methylation procedure for FAMEs preparation in the presence of internal standards to monitor the transesterification performance and analyte loss. FA profile was expressed as absolute concentration (g FAs/100g sample) and as relative concentration (weight $\%$ of total identified FAs).

The 6 fat extraction procedures of peanut butter (SRM ${ }^{\circledR} 2387$ ) can be considered effective, as the sistematic errors (bias) were not more than $\pm 2 \%$. From the point of view of experimentally determined values as absolute concentration ( $\mathrm{g} \mathrm{FAs} / 100 \mathrm{~g}$ ), in terms of saturated (SFA), monounsaturated (MUFA) and polyunsaturated (PUFA) fatty acids, individually or totally, all procedures of fat extraction were effective, accomplishing the conditions required for both results determined base on $\mathrm{RRF}_{i}(\mathrm{~g} / 100$ g) and those based on $F_{\text {. }}$ (weight \%).

When determining the composition in fatty acids as relative concentrations (weight $\%$ of total identified FAs) of peanut butter, based on the $F_{\text {i, }}$ for the 6 fat extraction methods of peanut butter, the condition that the absolute difference between 2 independent tests $(\Delta)$ to be less than or equal to the repeatability limit ( $r)(\Delta \leq r)$, as the sum of SFA/MUFA/ PUFA, and as individual fatty acids was fulfilled.

Acknowledgment: This work was performed through the Core Program, carried out with the support of the Ministry of Research and Innovation, project no. PN 16460101.

\section{References}

1.PEREZ-PALACIOS, T., RUIZ, J., MARTIN, D., MURIEL, E., ANTEQUERA, T., Food Chemistry, 110, 2008, p. 1025-1029

2.COGNAT, C., SHEPHERD, T., VERRALL, S.R., STEWART, D., Food Chemistry, 160, 2014, p. 72-81

3.PRIEGO-CAPOTE, F., LUQUE DE CASTRO, M.D., Talanta, 65, 2005, p. 98-103

4.PRIEGO-CAPOTE, F., RUIZ-JIMENEZ, J., LUQUE DE CASTRO, M.D., Food Chemistry, 100, 2007, p. 859-867

5.LUQUE-GARCIIA, J.L., LUQUE DE CASTRO, M.D., J ournal of Chromatography A, 1034, 2004, p. 237-242

6.DJ ENNI, Z., PINGRET, D., MASON, T.J., CHEMAT, F., Food Analytical Methods, 6, 2013, p. 1229-1233

7.SCHIAVON, S., PELLATTIERO, E., CECCHINATO, A., TAGLIAPIETRA, F., DANNENBERGER, D., NUERNBERG, K., NUERNBERG, G., 
BITTANTE, G., J ournal of Food Composition and Analysis, 50, 2016, p. 10-18

8.MAZUREK, S., SZOSTAK, R., KITA, A., J ournal of Molecular Structure, 1126,2016, p. 213-218

9.MANZANO, P., DIEGO, J.C., NOZAL, M.J., BERNAL, J.L., BERNAL, J., Journal of Food Composition and Analysis, 28, no. 1, 2012, p. 31-39 10.IONESCU (BORDEI), N., POPESCU, M., BRATU, A., ISTRATI, D., OTT, C., MEGHEA, A., Rev. Chim. (Bucharest), 66, no. 9, 2015, p. 12671272

11. RAICIU, A.D., POPESCU, M., IVOPOL, G.C, BORDEI, N., ALEXANDRU, G., CRISAN, I., MANEA, S., DIMA, S.O., Rev. Chim. (Bucharest), 67, no. 12, 2016, p. 2449-2453

12. IANCU, P., STEFAN, N.G., PLESU, V., TOMA, A., STEPAN, E., Rev. Chim. (Bucharest), 66, no. 6, 2015, p. 911-917

13.SALIMON, J., OMAR, T.A., SALIH, N., Arabian J ournal of Chemistry, 10, 2013, p. S1875-S1882

14.ZHANG, H., WANG, Z., LIU, O., J ournal of Pharmaceutical Analysis, 5, no. 4, 2015, p. 223-230

15.CRUZ-HERNANDEZ, C., GOEURIOT, S., GIUFFRIDA, F., THANKKAR, S.K., Journal of Chromatography A, 1284, 2013, p. 174-179

16.PETROVIC, M., KEZIC, N., BOLANCA, V., Food Chemistry, 122, 2010, p. 285-291

17.TOCIU, M., TODASCA, M.C., STANESCU, M.D., Rev. Chim. (Bucharest), 68, no. 9, 2017, p. 2002-2005
18.CHIRA, N.-A., BRATU, A., MIHALACHE, M., TODASCA, M.C., DORNEANU, A., ROSCA, S.I., Rev. Chim. (Bucharest), 65, no. 7, 2014, p. $774-778$

19.DELEANU, M., SANDA, G.M., STANCU, C.S., POPA, M.E., SIMA, A.V., Rev. Chim. (Bucharest), 67, no. 1, 2016, p. 8-12

20.CHIRA, N., NICOLESCU, A., STAN, R. , ROSCA, S., Rev. Chim. (Bucharest), 67, no. 7, 2016, p. 1257- 1263

21.***SR EN ISO 17189:2005 Butter, edible oil emulsions and spreadable fats - Determination of fat content

22.LINSINGER. T., European Reference Materials, application note 1, 2010

23.***SR EN ISO 12966-2:2011: Animal and vegetable fats and oils - Gas chromatography of fatty acid methyl esters - Part 2: Preparation of methyl esters of fatty acids

24.***SR EN ISO 12966-4:2015: Animal and vegetable fats and oils -Gas chromatography of fatty acid methyl esters - Part 4: Determination by capillary gas chromatography.

25.*** International Conference on Harmonisation of Technical Requirements for Registration of Pharmaceuticals For Human Use (ICH); Validation of Analytical Procedures: Text and Methodology Q2(R1); ICH: London. 2005

$\overline{\text { Manuscript received: } 14.11 .2017}$ 